\title{
Analisis Perbandingan Metode Desain Pelat Beton Konvensional terhadap Slab Steel Deck Komposit
}

\author{
Muhammad Sofyan ${ }^{1}$; Abdul Rokhman ${ }^{2}$; Ade Okvianti Irlan ${ }^{3}$ \\ ${ }^{1,2}$ Sekolah Tinggi Teknik PLN \\ ${ }^{3}$ Universitas Trisakti \\ ${ }^{1}$ m.sofyan@sttpln.ac.id
}

\begin{abstract}
Like other structures, floor slabs also develop over time. The shorter time demands of work with lower costs are one reason for the development of structures in the construction of houses. Floor plate work can be done with two methods the conventional floor tiles of many multilevel buildings use reinforcement to bear the positive moment. While for carrying positive reinforcement, other materials can be used, namely Steel Deck Slab which will cause a composite action on the plate. The research has been conducted on the design of composite steel decks in Indonesia. The purpose of this study was to find out and compare the Capacity Efficiency of the conventional plate design and the composite Composite Steel Deck Slab with variations in plate thickness 8, 10 and $12 \mathrm{~cm}$ and compare the nominal moment of the cross section. By comparing these two types of plates the design engineer can determine the optimal dimensions.
\end{abstract}

Keywords: Conventional Plates, Steel decks, Composites

\begin{abstract}
ABSTRAK
Seperti struktur lainnya, pelat lantai juga mengalami perkembangan dari waktu ke waktu. Tuntutan waktu pekerjaan yang lebih singkat dengan biaya yang lebih murah menjadi salah satu alasan terjadinya perkembangan struktur dalam pembangunan rumah. Pekerjaan plat lantai dapat dilakukan dengan dua metode Pelat lantai konvensional bangunan beton bertingkat banyak yang menggunakan tulangan untuk memikul momen positifnya. Sementara untuk memikul tulangan positif tersebut dapat digunakan bahan lain yaitu Slab Steel deck yang akan menimbulkan aksi komposit pada pelat. Telah penelitian yang dilakukan mengenai desain steel deck komposit di indonesiaTujuan penelitian ini ialah Mengetahui dan membandingkan Efisiensi Kapasitas Desain pelat konvensional dan Slab Steel Deck Komposit yang optimal dengan variasi tebal pelat 8, 10 dan $12 \mathrm{~cm}$ serta Membandingkan Momen nominal Penampangnya. Dengan membandingkan kedua jenis pelat ini engineer desain dapat menentukan dimensi yang optimal.
\end{abstract}

Kata kunci: Pelat Konvensional, Steel deck, Komposit 


\section{JURNAL FORUM MEKANIIKA}

Vol. 8, No. 1, Mei 2019, P-ISSN: 2356-1491, E-ISSN: 2655-8211

DOI: https://doi.org/10.33322/forummekanika.v8i1.428

\section{PENDAhuluan}

Dalam mendesain suatu bangunan, keekonomisan merupakan hal yang selalu ingin dicapai semaksimal mungkin. Pemilihan material, metode pelaksanaan, hingga dimensi komponen komponen bangunan menjadi pertimbangan dalam pencapaian tingkat keekonomisan suatu bangunan. Tanpa mengesampingkan hal kekuatan bangunan, kestabilan bangunan, efisiensi bangunan, serta waktu pelaksanaan, keekonomisan suatu bangunan dapat dicapai dengan perencanaan yang matang. Salah satu alternatif pemecahannya adalah pemilihan material bangunan pada pelat lantai. Suatu konstruksi bangunan, terutama yang terbuat dari beton, baja, atau keduanya tidak terlepas dari elemen - elemen pelat, kolom maupun balok kolom. Masing - masing elemen tersebut akan memikul gaya - gaya seperti momen, normal, lintang, walaupun persentasenya berbeda antara satu dengan yang lain.

Struktur yang memikul momen pada umumnya adalah kolom, balok dan pelat lantai. Selain akibat beban sendiri struktur tersebut, beban yang menambah besar momen yang harus dipikul adalah beban mati dan beban hidup yang pada umunya berada di atas pelat lantai. Jika diamati, pelat lantai bangunan beton bertingkat banyak yang menggunakan tulangan untuk memikul momen positifnya. Sementara untuk memikul tulangan positif tersebut dapat digunakan bahan lain yaitu Slab Steel deck yang akan menimbulkan aksi komposit pada pelat tersebut. Penelitian terdahulu telah dilakukan untuk mengetahui dimensi yang efisien dalam perencanaan pelat beton. Beberapa diantaranya meneliti tentang perbandingan metode konstruksi plat lantai sistem double wire mesh dengan sistem half slab [1]. Dalam kasus yang lain dilakukan studi tentang Perbandingan Efisiensi Penggunaan Hollow Core Slab (HCS) Dibandingkan Dengan Pelat Konvensonal In Situ Pada Proyek Pembangunan Gudang Ciwastra Bandung [2]. Serta studi mengenai mendesain pelat konvensional dua arah beton bertulang [3].

Berdasarkan beberapa hal yang melatar belakangi usulan penelitian ini, tujuan utama yang dapat dicapai adalah Mengetahui dan membandingkan Efisiensi Kapasitas Desain pelat konvensional dan Slab Steel Deck Komposit yang optimal dengan variasi tebal pelat 8, 10 dan $12 \mathrm{~cm}$ serta membandingkan Kekuatan Momen Nominal Pelat konvensional dan Slab Steel Deck Komposit.

\section{METODE/PERANCANGAN PENELITIAN}

\subsection{Gambaran Umum}

Jenis penelitian merupakan Tinjauan desain system Pelat Beton dan Pelat Komposit pada proyek Gedung Kantor Otoritas Bandara Udara Wilayah V Makassar. Teori dan rumus yang menunjang penelitian ini berdasarkan atas sejumlah jurnal ilmiah dan dokumen yang diterbitkan oleh SNI maupun ANSI. Dalam Penelitian ini akan Didesain Kapasitas Penampang Pelat Beton Konvensional dan Slab Steel deck Komposit kemudian dibandingkan momen nominalnya.

Alat bantu yang digunakan dalam desain dan analisis struktur adalah program komputer Auto Cad 2016 yang akan digunakan untuk menggambar detail lay out, desain dan Program Komputer Analisis Struktur untuk menghitung gaya dalam pelat secara otomatis.

\subsection{Lay Out Struktur pelat}

Dalam Penelitian Ini akan ditinjau pelat pada Gedung Kantor Otoritas Bandara Udara Wilayah V Makassar.panjang dan lebar pelat yang akan ditinjau adalah 8.4x6.3 m. Secara umum lay out Gedung dapat dilihat pada gambar 1. Area yang ditandai garis putus-putus merupakan area tinjauan pelat. 


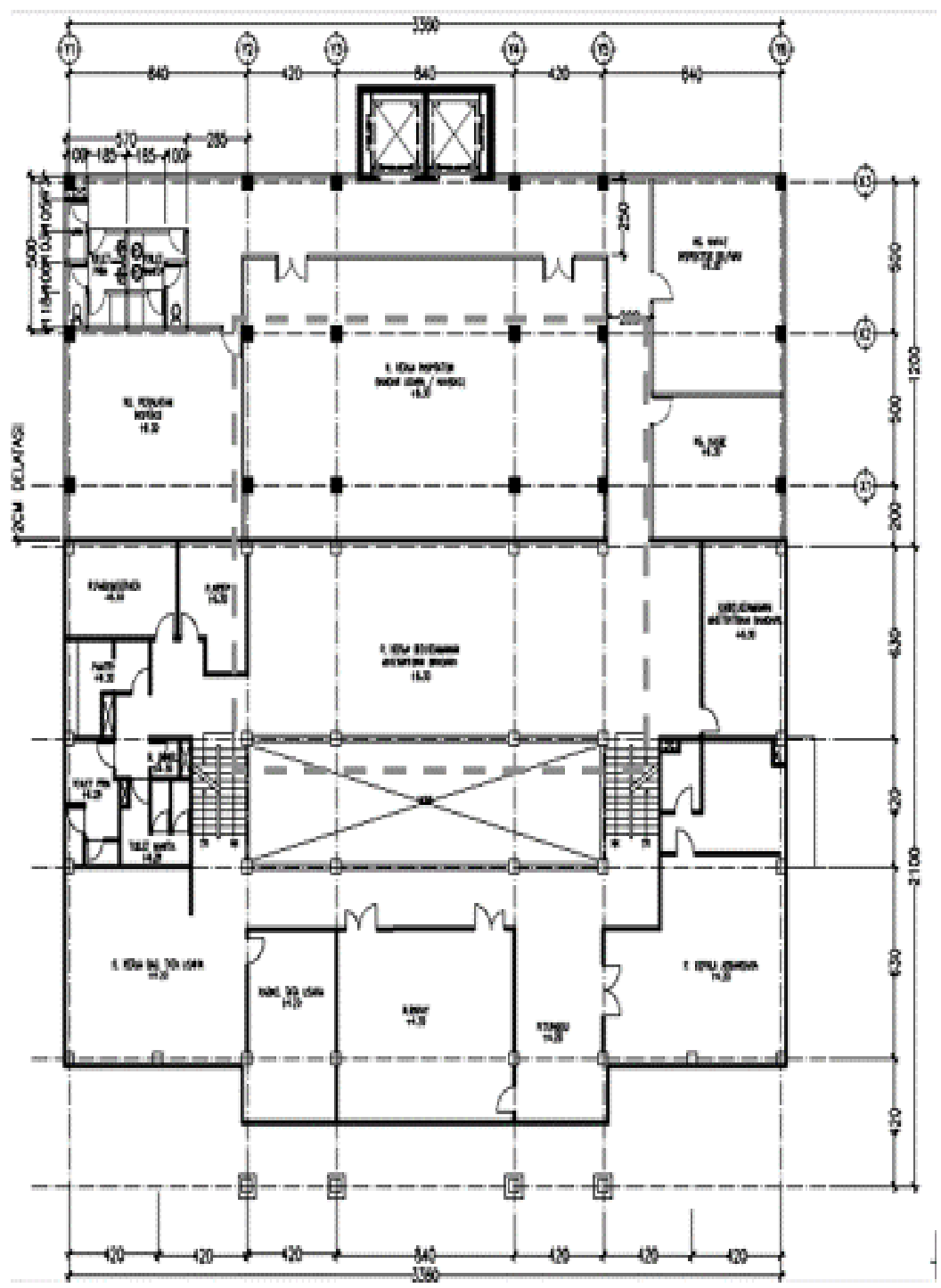

Gambar 1. Lay Out Gedung

Variasi dimensi pelat yang akan dipakai secara berturut-turut adalah pelat tebal 8, 10 dan 12 $\mathrm{cm}$. Pelat akan didesain sebagai pelat konvensional maupun sebagai pelat komposit steel deck. Untuk mempermudah penyajian data hasil Analisa maka dilakukan labeling model pelat seperti pada tabel 1 .

Tabel 1. Labeling Pelat

\begin{tabular}{|c|c|c|}
\hline No. & Label Model & Tebal $(\mathrm{cm})$ \\
\hline 1 & Pelat C1 & 8 \\
\hline 2 & Pelat C2 & 10 \\
\hline 3 & Pelat C3 & 12 \\
\hline 4 & Pelat SD1 & 8 \\
\hline 5 & Pelat SD2 & 10 \\
\hline 6 & Pelat SD3 & 12 \\
\hline
\end{tabular}




\subsection{Design Pelat 1 Arah}

As tulangan pelat 1 arah dapat dihitung dengan persamaan 1 [4].

$$
A_{s}=\frac{1000 A_{b}}{s}
$$

Dimana $A_{b}$ merupakan luas penampang tulangan yang dipakai. Kemudian dilanjutkan dengan menetukan rasio tulangan dengan menggunakan persamaan 2 .

$$
\rho=\frac{A_{s}}{b . d}
$$

Dengan mengetahui angka rasio tulangan dan As Tulangan maka momen nominal pelat Mn dengan persamaan 3.

$$
M_{n}=\emptyset A_{s} f_{y}\left(d-\frac{a}{2}\right)
$$

Dimana a dihitung dengan persamaan 4

$$
a=\frac{A_{s} f_{y}}{0.85 f_{c}^{\prime} . b}
$$

\subsection{Design Pelat Steel deck}

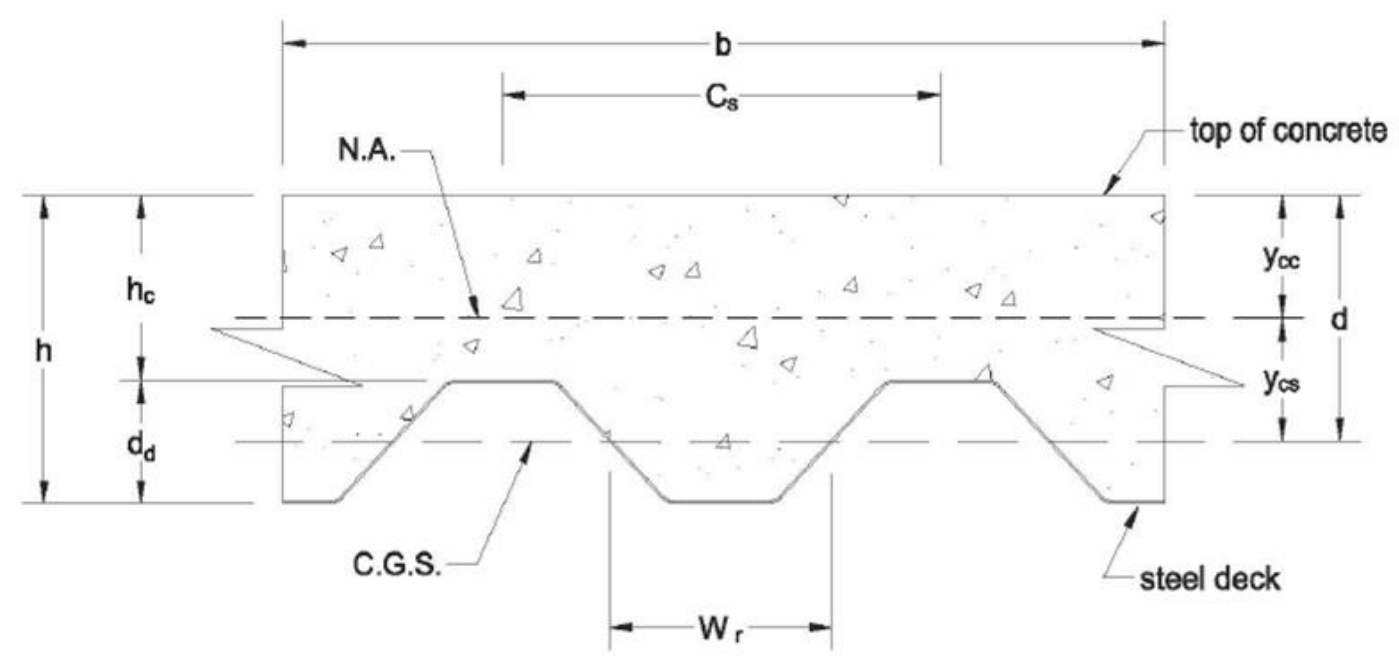

Gambar 2. Penampang pelat steel deck Komposit

Momen nominal atau momen tahanan merupakan tolak ukur kekuatan penampang pelat steel deck komposit dalam memikul beban momen. Langkah awal perhitungan dengan menentukan datadata propertis penampang yang tertera pada gambar 2 .

Untuk mengetahui posisi sumbu netral penampang dilakukan dilakukan perhitungan ycc terlebih dahulu dengan persamaan 4 berikut [5].

$$
y_{c c}=d\left\{\sqrt{2 \rho n+(\rho n)^{2}}-\rho n\right\} \leq h_{c}
$$

Dimana $n$ adalah:

$$
n=\frac{E_{s}}{E_{c}}
$$


selanjutanya dilakukan perhitungan momen inersia penampang komposit dan momen yield dengan rumus berikut.

$$
\begin{gathered}
I_{c r}=\frac{b}{3 n} y_{c c}^{3}+A_{s} y_{c s}^{2}+I_{s f} \\
M_{y}=\frac{F_{y} I_{c r}}{h-y_{c c}}
\end{gathered}
$$

Sehingga dapat dihitung momen nominal dengan persamaan berikut

$$
\emptyset_{s} M_{n o}=\emptyset_{s} K M_{y}
$$

\section{HASIL DAN PEMBAHASAN}

Berdasarkan Perhitungan sesuai dengan prosedur yang telah ditentukan diperoleh hasil rekapitulasi seperti pada tabel 2. Penjelasan tabel 2 disajikan secara grafis pada gambar 3 .

Tabel 2. Tabel Rasio Tulangan dan Rasio beban/kapasitas pelat konvensional.

\begin{tabular}{|c|c|c|c|c|}
\hline $\begin{array}{c}\text { Pelat } \\
\text { Konvensional }\end{array}$ & $\begin{array}{c}\text { Mu } \\
(\mathbf{N m m})\end{array}$ & $\begin{array}{c}\text { Mn } \\
(\mathbf{N m m})\end{array}$ & $\begin{array}{c}\text { Rasio } \\
\text { Tulangan( }(\mathbf{)})\end{array}$ & $\begin{array}{c}\text { Rasio } \\
\text { Beban/Kapasitas } \\
(\mathbf{M u} / \mathbf{M n})\end{array}$ \\
\hline CD1 & 10946502 & 11626365.18 & 0.209333333 & 0.941524013 \\
\hline CD2 & 11946690 & 16509693.18 & 0.152756757 & 0.723616718 \\
\hline CD3 & 12946878 & 21393021.18 & 0.120255319 & 0.60519166 \\
\hline
\end{tabular}

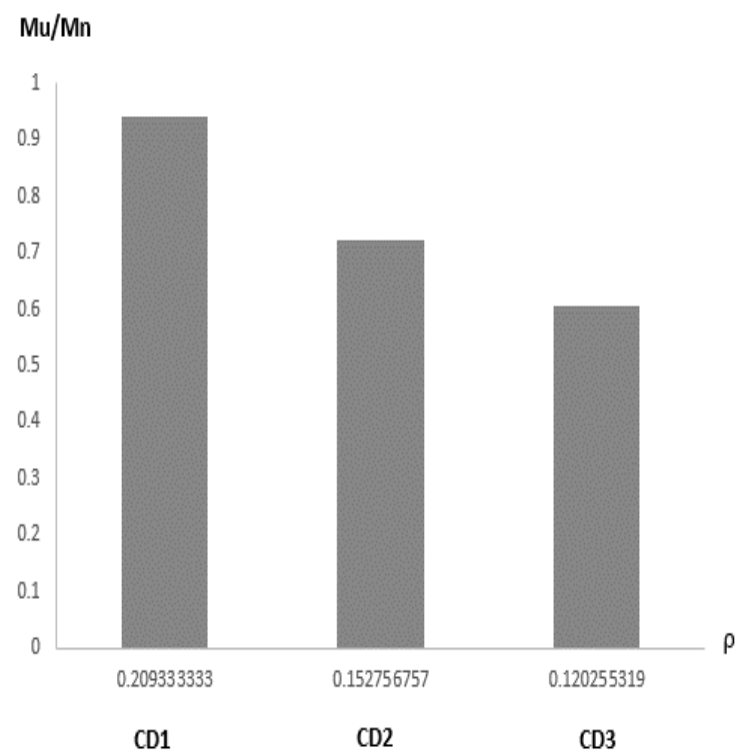

Gambar 3. Hubungan antara Rasio tulangan terhadap Mu/Mn pelat konvensional

Pada gambar 5.8 terlihat bahwa dengan konfigurasi tulangan diameter $12 \mathrm{~mm}$ per jarak 100 $\mathrm{mm}$ rasio tulangan terbesar terdapat pada pelat CD1 yaitu sebesar 0.209. Rasio tulangan terkecil terdapat pada pelat CD3 yaitu sebesar 0.120. Efisiensi Penampang dapat dilihat dari rasio $\mathrm{Mu} / \mathrm{Mn}$, semakin mendekati nilai 1 maka semakin efisien penampang pelat yang digunakan. Pada Grafik tersebut terlihat nilai efisiensi $\mathrm{Mu} / \mathrm{Mn}$ yang paling optimal terdapat pada pelat CD1 yaitu sebesar 
0.94. Jika ditinjau angka rasio tulangan, semakin besar rasio tulangan yang dipakai semakin efisien kekuatan penampang pelat.

Pada Tabel 3. disajikan rekapitulasi rasio beban/kapasitas slab steel deck yang terdiri dari SD1, SD2 dan SD3. Data Grafis pada tabel 3 disajikan pada gambar 4.

Tabel 3. Tabel Rasio Tulangan dan Rasio beban/kapasitas pelat Steel deck.

\begin{tabular}{|c|c|c|c|}
\hline Pelat Steel deck & Mu & \multicolumn{1}{c|}{ Mn } & Rasio Beban/Kapasitas \\
\hline SDI & 10946502 & 11722834 & 0.933776082 \\
\hline SD2 & 11946690 & 15133913.07 & 0.789398614 \\
\hline SD3 & 12946878 & 18624814.4 & 0.695141316 \\
\hline
\end{tabular}

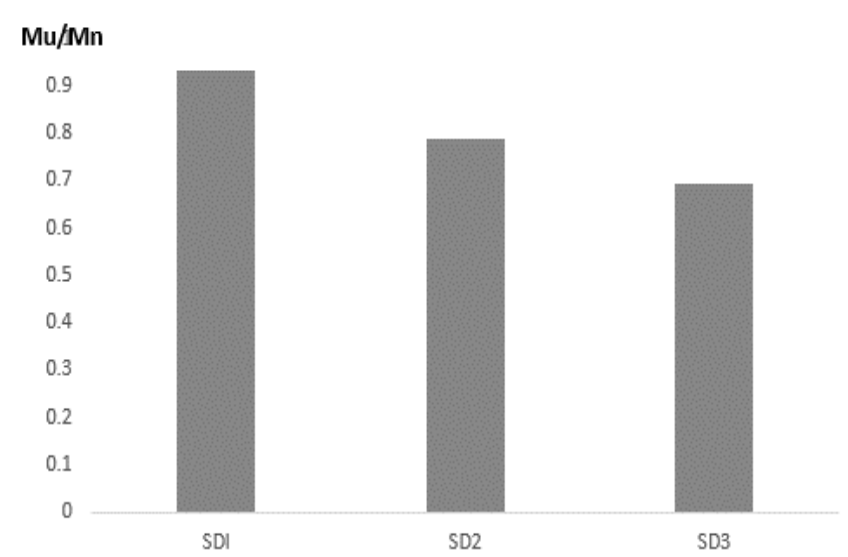

Gambar 4. Hubungan anatara Rasio tulangan terhadap Mu/Mn pelat Steel Deck

Pada Gambar 4 terlihat bahwa dengan penggunaan steel deck [5] Gage 2 Efisiensi terbesar terdapat pada pelat SDI yaitu sebesar 0.93 . Semakin besar ketebalan penampang efisiensi penampang semakin kecil. Demikian Pula sebaliknya. Untuk Mengetahui kekuatan panampang yang optimal digunakan momen nominal pelat disajikan pada gambar 5 .

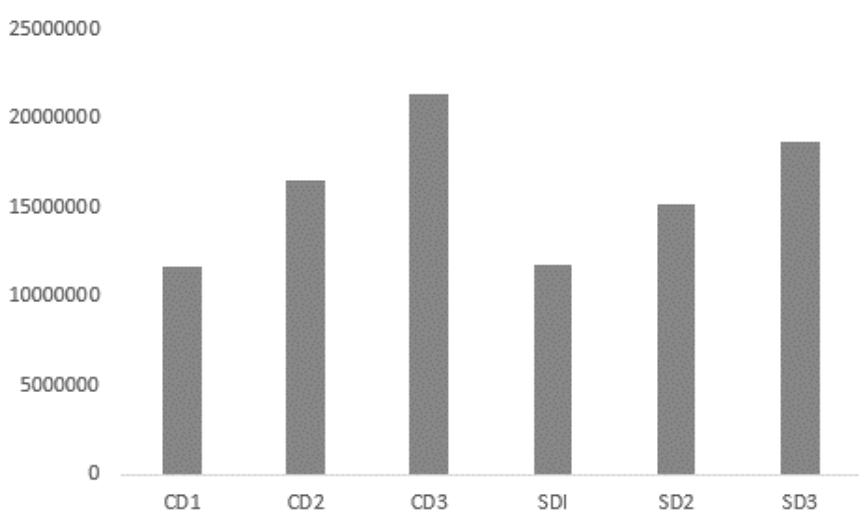

Gambar 5. Hubungan anatara Rasio tulangan terhadap Mu/Mn pelat Steel Deck

Dari gambar 5 terlihat selisih dari pelat CD1 dengan Pelat SD1 diperoleh sebesar 0.8\%. Untuk Pelat CD2 dan SD2 sebesar $8.33 \%$ serta pelat CD3 dan SD3 sebesar 12. $9 \%$. Berdasarkan angka angka tersebut diatas selisih kekuatan penampang dengan konfigurasi yang telah ditentukan tidak 
ada melampaui $15 \%$. Kekuatan Penampang baik pada pelat komposit maupun pelat steel deck kekuatannya tidak jauh berbeda jika memperhatikan angka rasio tulangan dan ketebalan penampang pelat.

\section{KESIMPULAN DAN SARAN}

Dengan konfigurasi tulangan diameter $12 \mathrm{~mm}$ per jarak $100 \mathrm{~mm}$ rasio tulangan terbesar terdapat pada pelat CD1 yaitu sebesar 0.209. Rasio tulangan terkecil terdapat pada pelat CD3 yaitu sebesar 0.120. terlihat nilai efisiensi Mu/Mn yang paling optimal terdapat pada pelat CD1 yaitu sebesar 0.94. Jika ditinjau angka rasio tulangan, semakin besar rasio tulangan yang dipakai semakin efisien kekuatan penampang pelat. Penggunaan steel deck standar ANSI 2011 Gage 2 Efisiensi terbesar terdapat pada pelat SDI yaitu sebesar 0.93. Semakin besar ketebalan penampang efisiensi penampang semakin kecil. Demikian Pula sebaliknya. Selisih dari pelat CD1 dengan Pelat SD1 diperoleh sebesar 0.8\%. Untuk Pelat CD2 dan SD2 sebesar $8.33 \%$ serta pelat CD3 dan SD3 sebesar 12. $9 \%$. Berdasarkan angka angka tersebut diatas selisih kekuatan penampang dengan konfigurasi yang telah ditentukan tidak ada melampaui 15\%. Kekuatan Penampang baik pada pelat komposit maupun pelat steel deck kekuatannya tidak jauh berbeda jika memperhatikan angka rasio tulangan dan ketebalan penampang pelat.

Adapun Saran-saran yang perlu dipertimbangkan sebaiknya Dilakukan Peninjauan yang lebih mendalam pada daerah tumpuan pelat. serta dilakukan Uji Experimental untuk memperoleh hasil analisis yang lebih Faktual.

\section{UCAPAN TERIMAKASIH}

Penulis mengucapkan terima kasih sebesar-besarnya kepada Sekolah Tinggi Teknik PLN Jakarta (STT-PLN) yang telah memberi dukungan moril maupun materil yang membantu pelaksanaan penelitian dan penulisan artikel.

\section{DAFTAR PUSTAKA}

[1] Michael Teja dkk. (2013). Perbandingan Metode Konstruksi Plat lantai system Double Wire Mesh dengan Sistem Half Slab. ComTech Vol.4 No. 2 Desember 2013: 888-895.

[2] Fakhri Firdaus dkk. 2017. Perbandingan Efisiensi Penggunaan Hollow Core Slab (HCS) Dibandingkan Dengan Pelat Konvensonal In Situ Pada Proyek Pembangunan Gudang Ciwastra Bandung.) e-Jurnal MATRIKS TEKNIK SIPIL/Desember 2017/1418

[3] Patricia dkk. 2018. Desain pelat konvensional dua arah beton. Jurnal Sipil Statik Vol.6 No.9 September 2018 (705-714) ISSN: 2337-6732.

[4] Badan Standarisasi Nasional, SNI 2847-2013. Persyaratan Beton Structural untuk Bangunan Gedung. BSN

[5] ANSI. 2011. Composite Steel Floor Deck Slabs. Steel deck Institute. 